\title{
Проблема хирургической инфекции у больных сахарным диабетом, оперированных на аорто-подвздошном сегменте
}

\begin{abstract}
Цель работы: проанализировать частоту и причины гнойно-септических осложнений у больных, которым выполнено эндопротезирование аорто-подвздошного сегмента.

Проведен анализ гнойно-септических осложнений у 54 больных, которые были оперированы по поводу ишемических поражений сосудов нижних конечностей на фоне сахарного диабета. У всех больных были выполнены вмешательства на аорто-подвздошном сегменте с использованием синтетических сосудистых протезов. В соответствии с классификацией гнойно-септических осложнений реконструктивных операций 5 случаев осложнений, имеющихся в нашей практике, мы условно разделили на 2 группы: протезный сепсис; инфицирование трансплантата без клинических и лабораторных проявлений сепсиса.

Частота гнойно-септических осложнений составила 9,2 \%, почти все больные имели III-IV степень ишемии и были оперированы по неотложным показаниям. В 3 случаях инфицирования трансплантата без бактериемии пациенты оперированы до развития аррозивного кровотечения, что позволило у 2 пациентов сохранить конечности, и один пациент выписан после выполнения высокой ампутации конечности.В двух случаях выполнена частичная резекция инфицированной части бифуркационного протеза из отдельного доступа с последующей повторной реконструкцией. В одном случае у пациента с нарастающей ишемией конечности снят инфицированный бифуркационный протез и выполнена операция подключично-бедренного экстраанатомического шунтирования с одной стороны и высокая ампутация контрлатеральной конечности. Протезный сепсис имел место у 2 больных, умер один больной.
\end{abstract}

Ключевые слова: ишемические поражения сосудов нижних конечностей; сахарный диабет; гнойно-септические осложнения.

Проблема послеоперационных гнойно-септических осложнений в реконструктивной хирургии аорты и артерий конечностей особенно актуальна у пациентов с сахарным диабетом, поскольку их диагностика, хирургическое лечение и профилактика имеют свои особенности и весьма сложный прогноз.

Следует подчеркнуть, что проблема гнойно-септических осложнений реконструктивных сосудистых операций не является оторванной от общих принципов диагностики профилактики и лечения, принятых в хирургической практике. Однако эти грозные осложнения, сочетаясь с нарушением магистрального кровообращения в конечностях и развитием ишемии на фоне нарушения углеводного обмена, занимают особое место в проблеме хирургической инфекции [1, 2].

Инфицирование сосудистых имплантатов обычно развивается в течение первых 14-30 суток после операции. По данным различных авторов, такие больные составляют 4,3-14 \% [3, 4, 5].

Особенность этих осложнений заключается в следующем:

1. Большинство современных операций на аорто-подвздошном сегменте выполняется с применением синтетических сосудистых протезов, роль которых в развитии и поддержании раневой инфекции чрезвычайно велика.

2. Инфекционные процессы в ишемизированных тканях на фоне сахарного диабета про- текают особенно неблагоприятно, тем более при наличии некротических изменений в дистальных отделах конечности. При ишемии конечностей IV степени оперируются до 45 \% пациентов с использованием сосудистых протезов.

3. Большинство реконструктивных вмешательств достаточно травматичны, длительны и часто сопровождаются кровопотерей, обусловленной порозностью протезов, что в определенной степени утяжеляет течение раннего послеоперационного периода и повышает риск развития раневой инфекции.

В отделении сосудистой хирургии за 5 лет выполнено 54 операции при окклюзии терминального отдела аорты и подвздошных артерий у пациентов страдающих сахарным диабетом. Частота гнойно-септических осложнений составила 9,2 \%. Осложнения развились у пациентов, оперированных в ургентном порядке преимущественно с III-IV степенью ишемии по Покровскому или в связи с прогрессирующей острой ишемией конечностей 1 б-2 б степени по Савельеву.

В соответствии с классификацией гнойно-септических осложнений реконструктивных операций 5 случаев осложнений, имеющихся в нашей практике, мы условно разделили на 2 группы: протезный сепсис; инфицирование трансплантата без клинических и лабораторных проявлений сепсиса. 


\section{ПОВІДОМЛЕННЯ}

Протезный сепсис - это разновидность хирургического сепсиса со свойственными ему общеизвестными фазами течения. В нашем отделении протезный сепсис имел место у 2 пациентов. У 3 пациентов с инфицированными сосудистыми имплантатами двухкратные бактериологические исследования крови оказались стерильными, при наличии клинических признаков сепсиса.

Один пациент умер от аррозивного кровотечения, развившегося из проксимального анастомоза. При этом летальность составила 1,9 \% от общего числа оперированных и 20 \% от случаев инфицирования имплантатов.

В 3 случаях инфицирования трансплантата без бактериемии пациенты оперированы до развития аррозивного кровотечения, что позволило у 2 пациентов сохранить конечности, и один пациент выписан после выполнения высокой ампутации конечности.

В двух случаях выполнена частичная резекция инфицированной части бифуркационного протеза из отдельного доступа с последующей повторной реконструкцией.

В одном случае у пациента с нарастающей ишемией конечности снят инфицированный бифуркационный протез, и выполнена операция подключично-бедренного экстраанатомического шунтирования с одной стороны и высокая ампутация контрлатеральной конечности.

\section{СПИСОК ЛИТЕРАТУРЫ}

1. Сухарев И. И. Хирургия атеросклероза сосудов у больных сахарным диабетом / И. И. Сухарев. - Киев, 1993. - 295 с.

2. Профилактика и лечение гнойных осложнений после реконструктивных сосудистых операций с использованием синтетических протезов : тез. докл. 8 Всеросс. съезда хирургов / Покровский А. В., Светухин А. В., Чупин А. В., Цветков О. В. - Краснодар, 1995. - С. 527-528.

3. Сепсис и нозокомиальная инфекция / В. Ф. Саенко, В. И. Десятерик, Т. А. Перцова [и др.]. - Кривой Рог, 2002.

\section{REFERENCES}

1. Sukharev, I.I. (1993). Khirurgiya ateroscleroza sosudov u bolnykh sakharnym diabetom [Surgery of atherosclerosis in patients with diabetes mellitus]. Kiev [in Russian].

2. Pokrovskiy, A.V., Svetukhin, A.V., Chupin, A.V., \& Tsvetkov, O.V. (1995). Profilaktika i lechenie gnoynikh oslozhneniy posle rekonstruktivnykh sosudistykh operatsiy s ispolzovaniem sinteticheskikh protezov [Prevention and treatment of septic complications after reconstructive vascular operations using synthetic prostheses] All-Russian Congress of Surgeons. Krasnodar [in Russian].
У пациента из первой группы, поступившего с аррозивным кровотечением из проксимального анастомоза, выполнена операция удаления инфицированного бифуркационного протеза с одномоментным выполнением экстраанатомического подключично-бедренного одностороннего шунтирования. При бактериологическом исследовании у пациента подтверждена бактериемия. В последующем в результате развития тромбоза шунта пациенту выполнена высокая ампутация.

Таким образом, анализируя все случаи гнойно-септических осложнений у пациентов, страдающих сахарным диабетом, с сосудистыми имплантатами, можно сделать следующие выводы:

Определяющим моментом в определении хирургической тактики в случае инфицирования трансплантата является определение клинической формы гнойно-септического осложнения.

В случае инфицирования трансплантата с сопутствующей бактериемией показано его удаление. Эту операцию необходимо произвести до развития аррозивного кровотечения. При установленной бактериемии выполнение реконструктивной операции не показано.

При инфицировании протеза без бактериемии показано удаление протеза с выполнением повторной реконструкции при условии адекватности путей оттока, коррекции гипергликемии и адекватной антибактериальной терапии.

-225 c.

4. Correlation between in vivo and in vitro efficacy of antimicrobical agents against foreign body infections / A. F. Widmer, R. Frei, Z. Rajacic, W. Zimmerli // Infect. Dis. - 1990. - Vol. 162. - P. 96-102.

5. Goeau-Brissonniere O. Comment preventir les infectionis de protese / O. Goeau-Brissonniere, J. C. Pechere, C. Leport In: E. Kiefer (Ed.) Les anevrismes de L”aorte abdominale sous-renale. Paris:AERCV. - 1990. - P. 143-153.

3. Sayenko, V.F., Desyaterik, I.V., Pertsova, T.A., Krivitskiy, Yu.M., \& Shapovalyuk, V.V. (2002). Sepsis i nozokomialnaya infektsiya [Sepsis and nosocomial infection]. Kryvyi Rih [in Russian].

4. Widmer, A.F., Frei, R., Rajacic, Z., Zimmerli, W. (1990). Correlation between in vivo and in vitro efficacy of antimicrobical agents against foreign body infections. Infect. Dis., 162, 96-102. 5. Goeau-Brissonniere, O., Pechere, J.C., \& Leport, C. (1990). Comment preventir les infectionis de protese. In: Kiefer, E. (Ed.) Les anevrismes de L'aorte abdominale sous-renale. Paris:AERCV. 
V. I. DESYATERIK, A. V. DAVIDENKO, V. A. SLOBODYANYUK, V. G., ZHELEZNYAK, A. B. BOGATYREV, V. V. KABACHENKO, A. N. PROKUDA, S. V. MALYUTA.

Dnipropetrovsk Medical Academy

Kryvyi Rih City Clinical Hospital No. 2

\title{
THE PROBLEM OF SURGICAL INFECTION IN PATIENTS WITH DIABETES, AFTER OPERATIONS ON THE AORTO-ILIAC SEGMENT
}

The aim of the work: to analyze the frequency and causes of purulent-septic complications in patients who underwent endoprosthetic repair of the aorto-iliac segment.

Analysis of purulent-septic complications in 54 patients who were operated for ischemic lesions of the vessels of the lower extremities in diabetes mellitus was conducted. All patients underwent interventions on the aorto-iliac segment using synthetic vascular prostheses. In accordance with the classification of purulent-septic complications of reconstructive operations 5 cases of complications available in our practice, we divided into 2 groups - prosthetic sepsis; infection of the graft without clinical and laboratory manifestations of sepsis. The frequency of purulent-septic complications 9.2 percent, almost all of these patients had grade III-IV ischemia and were operated on urgent indications. In 3 cases, infection of the graft without bacteremia patients were operated before the development of erosive bleeding, which allowed 2 patients to save limbs, and 1 patient was discharged after performing the high amputation of the limb. In two cases a partial resection of the infected portion of the bifurcation prosthesis from separate access and subsequent re-reconstruction. In one case in a patient with progressive limb ischemia removed the infected bifurcation prosthesis, and surgery was performed subclavianfemoral bypass grafting extraanatomical on the one hand, and high amputation of the contralateral limb. Prosthetic sepsis occurred in 2 patients, 1 patient died.

Key words: ischemic lesions of the vessels of the lower extremities; diabetes mellitus; purulent-septic complications.

\section{В. І. ДЕСЯТЕРИК, О. В. ДАВИДЕНКО, В. А. СЛОБОДЯНЮК, В. Г. ЖЕЛІЗНЯК, О. Б. БОГАТИРЬОВ,} В. В. КАБАЧЕНКО, О. М. ПРОКУДА, С. В. МАЛЮТА

дУ “Дніпропетровська медична академія МОЗ України”

Криворізька міська клінічна лікарня № 2 Дніпропетровської обласної ради

\section{ПРОБ.ЛЕА ХІРУРГІЧНОЇ ІНФЕКЦІЇ У ХВОРИХ НА ЦУКРОВИЙ ДІАБЕТ, ОПЕРОВАНИХ НА АОРТО-К.УУБОВОМУ СЕГМЕНТІ}

\begin{abstract}
Мета роботи: проаналізувати частоту і причини гнійно-септичних ускладнень у хворих, яким було виконано ендопротезування аорто-клубового сегмента.

Проведено аналіз гнійно-септичних ускладнень у 54 хворих, які були оперовані з приводу ішемічних уражень судин нижніх кінцівок на тлі цукрового діабету. У всіх хворих були виконані втручання на аорто-клубовому сегменті з використанням синтетичних судинних протезів. Відповідно до класифікації гнійно-септичних ускладнень реконструктивних операцій 5 випадків ускладнень, наявних у нашій практиці, ми умовно розділили на 2 групи: протезний сепсис; інфікування трансплантата без клінічних та лабораторних проявів сепсису.

Частота гнійно-септичних ускладнень становила 9,2 \%, майже всі хворі мали III-IV ступінь ішемії і були оперовані за невідкладними показаннями. У 3 випадках інфікування трансплантата без бактеріємії пацієнти оперовані до розвитку арозивної кровотечі, що дозволило у 2 пацієнтів зберегти кінцівки, і одного пацієнта виписали після виконання високої ампутації кінцівки. У двох випадках виконана часткова резекція інфікованої частини біфуркаційних протеза 3 окремого доступу 3 наступною повторною реконструкцією. В одному випадку у пацієнта з наростаючою ішемією кінцівки знятий інфікований біфуркаційний протез, і виконана операція подключично-стегнового екстраанатомічного шунтування з одного боку, і висока ампутація контрлатеральної кінцівки. Протезний сепсис мав місце у 2 хворих, помер один хворий.
\end{abstract}

Ключові слова: ішемічні ураження судин нижніх кінцівок; цукровий діабет; гнійно-септичні ускладнення. 